\title{
Implicit Theories of Emotional Intelligence, Ability and Trait-Emotional Intelligence and Academic Achievement
}

\author{
Ana Costa and Luísa Faria \\ University of Porto, Faculty of Psychology and Education Sciences, Porto, Portugal
}

\begin{abstract}
This study examines the effect of the implicit theories of emotional intelligence and of emotional intelligence (EI; ability and trait EI) on students' academic achievement (GPA). Five hundred twenty-three $10^{\text {th }}$ graders $\left(M_{\text {age }}=15.5 ; S D=0.67\right)$ completed measures of implicit theories $($ IT $)$ and EI (performance and self-report). The results confirmed the direct effect of EI (ability and trait EI) on students' GPA. Moreover, implicit theories of EI affected students' trait EI and only indirectly affected students' achievement. Multigroup analyses indicated that the IT and EI effects on students' GPA were similar across students' gender and socio-professional status. These findings underline the relevance of students' implicit theories and EI and suggest their usefulness as strategies to foster academic success.
\end{abstract}

Keywords: implicit theories of emotional intelligence, ability EI, trait EI, academic achievement, secondary school

\section{Introduction}

Currently, there is broad agreement that not only cognitive abilities are responsible for students' academic achievement but also that a diverse array of emotional, motivational, and contextual factors influence student's achievement (Lau \& Roeser, 2002).

More specifically, students' implicit theories can either reinforce or undermine their emotional and academic outcomes (Romero, Master, Paunesku, Dweck, \& Gross, 2014): students that hold incremental theories concerning different personal

Ana Cristina Fontes Costa, Faculty of Psychology and Educational Sciences of the University of Porto, Rua Alfredo Allen, 4200-135 Porto, Portugal. E-mail: ana.fontescosta@gmail.com

This study was funded by the Portuguese Science Foundation (Postdoctoral Grant awarded to Ana Costa) SFRH/BPD/117479/2016; and CPUP UID/PSI/00050/2013; FEDER/COMPETE2020 POCI-01- 0145-FEDER-007294). 
or life-domains evidenced better mental health, well-being and academic attainment (Dweck, 2012), as opposed to students with entity or fixed theories. Moreover, several studies highlighted the adaptive role of emotional intelligence (EI) in school context since it promotes better academic adjustment and achievement, pro-social behaviours, less stress, and better outcomes on evaluations (Costa \& Faria, 2015; Greenberg et al., 2003). Nonetheless, the predictive validity of these constructs in educational settings is far from consistent. Therefore, the present study sought to extend previous work that focused on the predictive validity of EI in educational settings (Costa \& Faria, 2015), by examining the effect that implicit theories of emotional intelligence and EI (ability and trait EI) can have on students' academic achievement.

\section{Implicit Theories}

Individuals develop implicit theories (IT) about different personal attributes. These implicit beliefs affect individuals' everyday behaviour since they provide a conceptual framework or meaning system to interpret themselves, others and the world (Dweck, 2012). Based on the possibility of change of important domains such as intelligence, emotion, personality, and health, two personal conceptions can emerge (Dweck, 2012) and influence different personal motivational and behavioural responses (Crum, Salovey, \& Achor, 2013): entity theorists believe those attributes are predetermined, relatively fixed and hardly changeable, and tend to focus in the present reality; individuals with incremental theories tend to focus on the desired future, consider possible the malleability of these characteristics through learning and training, when conveying enough effort, investment and time (Dweck \& Legget, 1988; Sevincer, Kluge, \& Oettingen, 2014). In general, the literature has shown that an incremental perspective or a ,growth mindset" tends to be associated with more positive outcomes and performance in different domains (Cabello \& Fernández-Berrocal, 2015; Dweck, 2012).

Based on Dweck's original and most researched theoretical model of implicit theories of intelligence (1999), the literature has highlighted that incremental theorists prioritize their intellectual development (Robins \& Pals, 2002) valuing effort in face of challenging difficulties which allows them to accomplish progress and the development of new skills (Hong, Chiu, Dweck, Lin, \& Wan, 1999). The students' specific incremental motivational and behavioural response pattern lead them to higher academic achievement (Burnette, O'Boyle, VanEpps, Pollack, \& Finkel, 2013; Costa \& Faria, 2018). Several studies have explored the direct impact of implicit theories of intelligence on academic achievement and performance (Costa \& Faria, 2018; Sisk, Burgoyne, Sun, Butler, \& Macnamara, 2018; for a review) and reported the significant yet weak predictive validity of implicit theories of intelligence. 
Nonetheless, implicit theories' literature has also been exploring the relationship with diverse self-regulatory mediating processes (e.g., goal setting, goal operating, and goal monitoring; see Burnette et al., 2013, for a review), which in turn affects indirectly achievement. Specifically, research has evidenced that incremental theorists tend to focus more on learning goals (Dweck \& Leggett, 1988), use mastery-oriented response patterns to attain these goals (Henderson \& Dweck, 1990; Robins \& Pals, 2002), and manifest greater confidence and expectations when assessing their potential success, whereas entity theorists employ helpless oriented strategies to goals pursuits and report less confidence in the possibility of attaining those goals (Nussbaum \& Dweck, 2008; Thompson \& Musket, 2005). In a recent metanalytic review, the findings indicated that the incremental theorists have a stronger link to goal achievement through the tendency to adopt mastery-oriented strategies, to experience less negative emotion regarding one's goal pursuit, and report more positive success expectations (Burnette et al., 2013).

The effects of implicit theories of emotion-related attributes have more recently been addressed in the literature. Individuals with growth mindset reported more positive emotions, received more social support and used more mastery-oriented strategies than the entity theorists (De Castella et al., 2013; Kappes \& Schikowski, 2013; Romero et al., 2014; Tamir, John, Srivastava, \& Gross, 2007). In a precursory study in the field of implicit theories of emotional intelligence, the results indicated that the individuals with an incremental perspective of emotional intelligence presented higher emotional intelligence abilities (assessed via performance measures; Cabello \& Fernández-Berrocal, 2015).

Research has also pointed out that implicit theories of different essential features are related but distinct constructs (Cabello \& Fernández-Berrocal, 2015; Romero et al., 2014).In a study exploring the impact of implicit theories of intelligence and emotion on academic and emotional outcomes (Romero et al., 2014) it was found that academic achievement and the choice of advanced math courses was predicted by implicit theories of intelligence, while the fewer depressive symptoms and the tendency to improve well-being over time was predicted by implicit theories of emotions. The fact that the different implicit theories can affect differently academic and emotional outcomes argues for the domain-specificity of the construct (Romero et al., 2014).

The literature has explored different possible moderators that can overshadow this general link between implicit theories and different outcomes (Costa \& Faria, 2018; Sisk et al., 2018). In particular, some studies reported that gender does not mediate the relation of implicit theories of intelligence with academic achievement (Costa \& Faria, 2018) or presented inconclusive results considering goalachievement prediction (see Burnette et al., 2013, for a review), while other studies reflected girls' tendency to have a more fixed perspective of intelligence and ability (Dweck, 1999; Pepi, Faria, \& Alesi, 2006). In the emotion-related literature, women 
presented higher levels of incremental implicit theories of emotion and of emotional intelligence when compared to men (Cabello \& Fernández-Berrocal, 2015).

Also, the effects of socioeconomic backgrounds on the implicit theories' framework remain scarce in the literature. In a cross-national study developed in Chile (Claro, Paunesku, \& Dweck, 2016), researchers found that scholars from lowincome backgrounds tend to have a more entity-implicit theory of intelligence. Nevertheless, another study's crucial finding was that the type of IT that students endorse, specifically if incremental, can buffer the negative effect of their disadvantaged backgrounds, representing a more important predictor of their success than their economic provenance.

\section{Emotional Intelligence}

Emotional Intelligence (EI) has been widely acknowledged as a relevant factor in the academic context since it supports students' cognitive and social development (Mavroveli \& Sánchez-Ruiz, 2011; Mestre, Guil, Lopes, Salovey, \& Gil-Olarte, 2006): students with higher emotional competence have increased levels of motivation, stress regulation and self-discipline, define greater academic goals, which lead them to achieve higher achievement (Duckworth \& Seligman, 2005; Elliot \& Dweck, 2005), less school refusal behaviours (Díaz-Herrero et al., 2018) and better outcomes on evaluations (Greenberg et al., 2003). Emotional abilities not only improve students' academic endeavours, regulate emotions in themselves and in others and contribute to maintain their intrinsic motivation to achieve better academic outcomes (Rode et al., 2008), but also positively influence social school interactions (Argyle \& Lu, 1990).

Over the last decades, the field of EI has progressed and developed based on the distinction of its most common theoretical models: ability EI (cognitive-emotional ability) and trait EI (or trait emotional self-efficacy) (Mavroveli, Petrides, Shove, \& Whitehead, 2008). Ability EI is often defined as an interrelated set of emotion-related cognitive abilities that include the ability to perceive, appraise and express emotion, to use emotion to facilitate thought, understand emotion and regulate emotions in ourselves and others (Mayer \& Salovey, 1997), and should be assessed through maximum performance tests (Mayer, Caruso, \& Salovey, 1999). The trait EI model assesses people's perceptions of their emotional abilities and skills, conceptualized as a constellation of emotional perceptions measured through questionnaires and self-rating scales (Petrides, Pita, \& Kokkinaki, 2007).

Although a vast literature addresses the positive impact of EI in the educational context, the predictive validity of EI over academic achievement is inconsistent across studies. Actually, research often confirms the predictive validity of EI over students' achievement, above personality traits and general mental abilities (e.g., GilOlarte, Martin, \& Brackett, 2006; Mestre et al., 2006; Perera \& DiGiacomo, 2013; Song et al., 2010), yet others studies revealed that EI have limited validity in this 
context (Brackett, Mayer, \& Warner, 2004; O'Connor \& Little, 2003; Van Rooy \& Viswesvaran, 2004). Research has pointed out that this divergence in results can be explained by the different assessment methodologies used, underlying different EI's conceptualizations. In fact, the trait model assessed via self-report measures is not highly associated with psychometric intelligence (Petrides, Frederickson, \& Furnham, 2004), and the performance measures of EI's ability-based model tend to be more predictive of academic achievement (Costa \& Faria, 2015; Song et al., 2010).

While there is a general idea that females outperform males concerning emotional skills, the literature only partially supports this case. In fact, ability and trait EI appear to diverge across gender (Costa \& Faria, 2015; Costa, Faria, \& Takšić, 2011; Fernández-Berrocal, Cabello, Castillo, \& Extremera, 2012), but the effect size of those differences varies greatly across studies. In a meta-analytic review, a moderate effect size was found for ability EI's gender differences (Joseph \& Newman, 2010). In the academic context, gender can also exert effects on the trait EI prediction of academic outcomes although they tend to be subject- or gradespecific (Costa \& Faria, 2015; Petrides, Sanchez-Ruiz, Siegling, Saklofske, \& Mavroveli, 2018).

The individuals' socioeconomic position is frequently related to better EI abilities (Côté, Gyurak, \& Levenson, 2010), plausibly because economic difficulties can foster conflict within the family, which leads to poorer abilities to regulate and manage emotions (see Morris, Silk, Steinberg, Myers, \& Robinson, 2007, for a review). However, the clues to students' economic status in EI's validity prediction require further elaboration in the literature.

\section{The Current Study}

The present study contributes to the understanding of the predictive validity of IT and EI in the academic context by exploring their effect on secondary school firstyear students' academic achievement. Due to the influence that students' IT can have on different outcomes, particularly in challenging situations such as the transition to the secondary school cycle, the implicit theories of emotional intelligence (ITEI) will be examined in terms of their predictive validity on academic achievement. Also, as established in prior studies, the effect of EI (ability and trait EI models) on students' achievement will be explored. This study also intends to clarify whether IT has an effect on EI, thus whether it can have importance on students' emotional perceptions and objective performance in the academic context, and, in turn, indirectly predict students' achievement.

Within these general parameters, specific objectives were defined (cf. Figure 1): a) to explore whether and how ITEI and EI (ability and trait models) predict students' academic achievement (GPA); b) to examine the effect of ITEI on ability and trait 
EI; c) to explore whether students' gender and socio-professional status differ on the effect of ITEI and EI on their final year achievement.

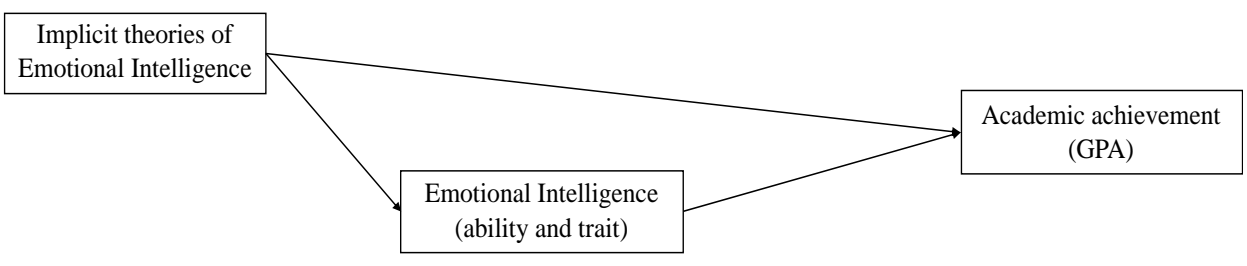

Figure 1. The model representing the interrelationship of the variables in the study.

Note. GPA = Grade Point Average.

\section{Method}

\section{Participants}

The participants of this study were $52310^{\text {th }}$-graders aged between 14 and 18 years old $\left(M_{\text {age }}=15.5 ; S D=0.67\right)$ in the Portuguese secondary academic cycle. Female students accounted for $56.0 \%$ of the sample; $34.3 \%$ were from a high socioprofessional status (33.7\% from middle and $32.1 \%$ from low statuses), and students attended different academic courses (69.6\% Science and Technologies, 21.7\% Languages and Humanities and 9\% the remaining courses).

\section{Measures}

Implicit Theories of Emotional Intelligence Scale (ITEIS). This scale assesses students' implicit theories about the malleability of emotional intelligence and was developed and adapted to the Portuguese context by Costa and Faria (2020) based in Dweck's conceptualization of implicit theories of intelligence (1999). In the original study, the instrument provided very good psychometric validity, confirming a twofactor structure (Costa \& Faria, 2020). ITEIS comprises 12 items: six incremental (e.g., Every time I learn with new experiences my emotional intelligence increases.) and six entity (e.g., My emotional intelligence is something about me, that I personally can't change very much) rated on a 6-point Likert-type scale, ranging from 1 (strongly agree) to 6 (strongly disagree). The incremental items were reversescored so that the average score indicated a measure of students' incremental perceptions. In this study, ITEIS total scale $(\alpha=.89)$, incremental $(\alpha=.82)$ and entity $(\alpha=.85)$ dimensions presented very good internal consistency.

The Emotional Skills and Competence Questionnaire (ESCQ) is a self-report scale of EI, with 42-item grounded on Mayer and Salovey's (1997) model, and 
includes three dimensions: Perceive and Understand Emotion (14 items, e.g., When I see how someone feels, I usually know what has happened to him.), Express and Label Emotion (14 items, e.g., I am able to express my emotions well.), and Manage and Regulate Emotion (14 items, e.g., When I am in a good mood, every problem seems soluble.). This scale was originally developed by Takšić, Mohorić, and Duran (2009a) in Croatia but is currently adapted and validated in different cultural contexts (Faria et al., 2006; Takšić et al., 2009b). ESCQ has repetitively exhibited sound psychometric properties within studies in different contexts, corroborating the threefactor underlying structure, indicating adequate internal consistency (from .72 to .92), moderate correlations among the subscales (from .49 and .54; Faria et al., 2006; Takšić et al., 2009) as well as displaying absolute and relative satisfactory fit indices $(\mathrm{NNFI}=.93 ; \mathrm{CFI}=.94 ; \mathrm{RMR}=.04 ; \mathrm{RMSEA}=.04 ;$ Stocker $\&$ Faria, 2012).

The Vocabulary of Emotions Test (VET) is a test grounded on the Understand Emotion branch of EI's ability conceptualization. This measure assesses students' emotional knowledge through a vocabulary of emotions test. Created by Takšić, Harambašić, and Velemir (2003) in Croatia for the secondary school academic setting, this test has the same format as other classic vocabulary tests and includes 35 items, which refer to target words saturated emotionally. The task presented in the test requests that the subjects choose an adjective (from six presented) with the closest meaning to the target word (emotion). The original version of the test presented adequate psychometric properties: strong association with other intelligence tests (e.g., California Tests of Mental Maturity) and 44\% of specific predictive power over classic intelligence tests (Takšić \& Mohorić, 2008), strong correlations with other EI tests (Analysis of emotions test) and good reliability ( $\alpha=$ .90; Takšić \& Mohorić, 2008). VET was adapted to the Portuguese context with adequate psychometric properties: items' difficulty $(M=0.55 ; S D=0.22)$, reliability above .71 and presented differential validity for gender and cultural context (Costa, Faria, \& Takšić, 2011).

Academic Achievement. The students' final grades (from 0 to 20) were collected at the end of the academic year from the school's official records. The Grade Point Average (GPA) used in the study was obtained from the student's grades average from all the subjects taken.

\section{Procedure}

The present study was introduced to various public schools with secondary school cycle. After formal approval, schools agreeing to collaborate in this study selected classes to participate according to their availability. The measures were filled out individually by the participants in collective administrations in the classrooms on school hours with the presence of one researcher and the class teacher. Before filling out the questionnaire, students were informed of study's voluntary nature and purpose, and the confidentiality and the anonymity were guaranteed. 
Since the majority of the sample comprised minors, only those adolescents authorized by the informed consent of their parents or legal guardians joined the study. The Portuguese National Data Protection Commission and the DirectorateGeneral for Education approved this study and the Ethics Committee of the Faculty accepted its execution.

\section{Data Analyses}

Prior analyses were conducted to obtain descriptive statistics and confirm the assumptions underlying maximum likelihood procedures. The association between study variables was tested with Pearson's correlations.

To explore the effects of ITEI and EI (ability and trait) in students' academic achievement, path analysis was conducted using AMOS 25.0 software. The structural models were tested using maximum likelihood estimation, given the method's robustness to normality deviations. Chi-square $(\chi 2)$, Confirmatory Factor Index (CFI), Goodness of Fit (GFI), Tucker-Lewis Index (TLI), and Root Mean Square Error of Approximation (RMSEA; and 90\% Confidence Interval) were considered to assess goodness-of-fit indices (Hu \& Bentler, 1999). Hu and Bentler (1999) recommended for an adequate model fit a RMSEA of .08 or less and a CFI, GFI and TLI of .95 or more, although values over .90 are considered acceptable.

Multigroup analysis examines the possible effect of students' gender and socioprofessional status (low, medium and high) in the proposed model. The initial model that admits the structural paths to diverge across groups was compared with a subsequent model that constrains to be equal to the structural paths across groups. Significant chi-square differences between the model with free structural paths and the model with structural paths constrained to be equal across groups determine if the model differs across groups. Critical ratios of differences (CRD) were used to assess if there were differences among the parameter estimates across groups, reducing the probability of error type $\mathrm{I}$.

\section{Results}

\section{Descriptive Analyses}

All variables were within the acceptable limits of univariate normality (skewness and kurtosis values $<|1|$, respectively) and seven cases were identified as multivariate outliers (Mahalanobis distance with $p<.001$ ) and excluded from subsequent analyses.

The descriptive statistics and correlations for all the variables were presented in Table 1. In general, only the trait EI was related to student's implicit theories of EI. 
Students' GPA was associated at a moderate level with EI ability measure and with MRE trait dimension at a lower level.

Table 1

Descriptive Statistics and Zero-Order Correlations for all Variables in the Study

\begin{tabular}{lccccccc}
\hline Measure & \multicolumn{1}{c}{$M(S D)$} & 1 & 2 & 3 & 4 & 5 & 6 \\
\hline 1. VET (ability EI) & $21.81(4.25)$ & - & & & & & \\
2. EE (trait EI) & $57.88(11.58)$ & -.01 & - & & & & \\
3. PUE (trait EI) & $63.06(8.63)$ & .04 & $.28^{* *}$ & - & & & \\
4. MRE (trait EI) & $63.01(8.02)$ & $.11^{*}$ & $.50^{* *}$ & $.34^{* *}$ & - & & \\
5. ITEI & $54.63(9.28)$ & .08 & $.26^{* *}$ & $.20^{* *}$ & $.30^{* *}$ & - & \\
6. GPA & $13.34(2.77)$ & $.45^{* *}$ & -.07 & -.04 & $.10^{*}$ & .07 & - \\
\hline
\end{tabular}

Note. VET $=$ Vocabulary of Emotions Test $; \mathrm{EE}=$ Emotional Expression; PUE $=$ Perceive and Understand Emotion; MRE = Manage and Regulate Emotion; ITEI = Implicit Theories of Emotional Intelligence; GPA $=$ Grade Point Average; $N=523 ;{ }^{*} p<.05 ;{ }^{* *} p<.001$.

\section{Path Analysis}

The present study hypothesized that students' ITEI and EI have an effect on students' academic achievement (GPA). In particular, to explore the interrelationships between variables, a model comprising the effect of ITEI and the ability (VET) and trait EI components (emotional expression [EE], perceive and understand emotion [PUE] and manage and regulate emotion [MRE]), on students' GPA was estimated using multiple regression analyses.

The first path model revealed satisfactory fit indices, but the existence of nonsignificant paths led to a subsequent model. The second model excluded the nonsignificant paths between ITEI and GPA, ITEI and the EI's ability to measure VET, and between the PUE trait EI and GPA. These changes provided an improvement in the model fit indices $\left(\chi^{2}(5, N=523)=7.862, p=.164 ; \mathrm{CFI}=.993, \mathrm{NFI}=.982, \mathrm{GFI}\right.$ $=.995$, RMSEA $=.033)$.

The results evidenced that ITEI has a positive effect on all students' EI trait dimensions (PUE, EE, MRE; cf. Fig. 2), but not the ability EI VET ( $p=.066)$. The EI variables, with the exception of PUE, predicted directly students' GPA from low (MRE $\beta=.11, p<.01$ ) to moderate levels (VET $\beta=.44, p<.001$ ). The EE trait EI predicted negatively students' GPA $(\beta=-.12, p<.01)$. ITEI did not represent a direct effect on students' academic achievement $(p=.375)$. 


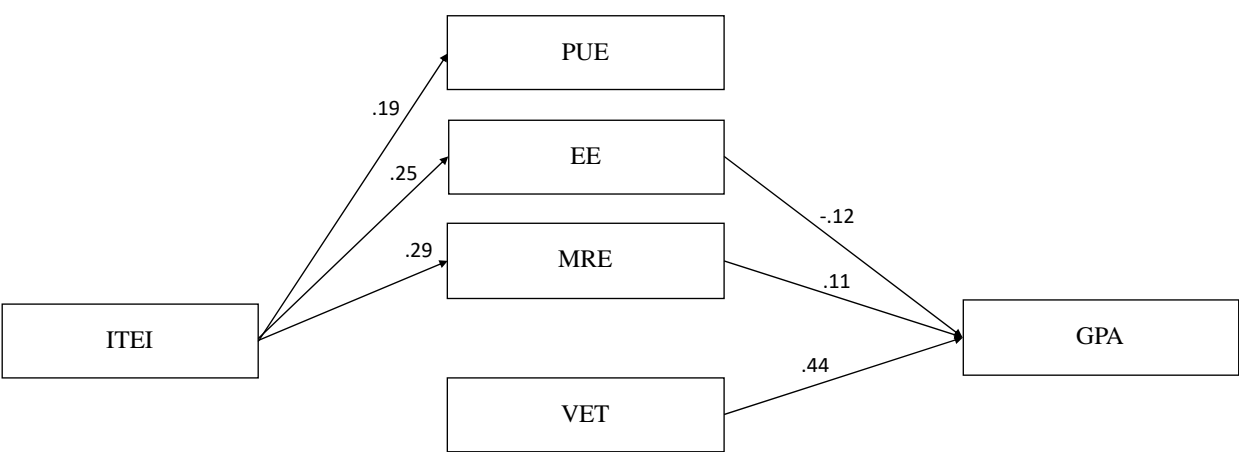

Figure 2. Path model depicting relationships between the ITEI and EI variables and students' grade point average.

Note. ITEI = Implicit Theories of Emotional Intelligence; PUE = Perceive and Understand Emotion; $\mathrm{EE}=$ Emotional Expression; $\mathrm{MRE}=$ Manage and Regulate Emotion; VET = Vocabulary of Emotions Test; GPA = Grade Point Average.

\section{Multigroup Analyses}

To explore whether the hypothesized model or coefficient paths differ significantly across students' gender and socio-professional status multigroup moderation analyses were conducted.

\section{Gender Differences}

The implicit theories and EI model previously defined (cf. Fig. 2) was established for the gender groups and exhibited suitable fit indices (CFI $=.977$, NFI $\left.=.956, \mathrm{GFI}=.988, \mathrm{RMSEA}=.043, \chi^{2}(10, N=293)=19.492, p=.034\right)$. The multigroup gender moderation analysis showed non-significant chi-square differences between the unconstrained model and the constrained one, $\Delta \chi^{2}(6, N=$ 293) $=6.637, p=.356$, suggesting that the model did not diverge across gender.

\section{Socio-Professional Status Differences}

The previously defined model of implicit theories and EI (cf. Fig. 2) estimated through the socio professional status groups (low, medium, and high) obtained good fit $\left(\mathrm{CFI}=.997, \mathrm{NFI}=.955, \mathrm{GFI}=.987, \mathrm{RMSEA}=.012, \chi^{2}(18, N=171)=19.183\right.$, $p=.381)$. The non-significant chi-square differences across the models (unconstrained vs. constrained), $\Delta \chi^{2}(12, N=171)=18.357, p=.105$, implied that the final model did not diverge, considering students' socio-professional status. 


\section{Discussion}

While the literature has always searched for factors that promote students' achievement in the academic context, particular interest has been devoted to explore to what extent students' motivational and emotional features can impact their development. The present study aimed at extending the effects of implicit theories (IT), particularly by addressing the lack of studies of IT in the emotional intelligence field, and joining together IT and students' emotional experience (ability and trait EI) to investigate their effect on academic achievement.

As the literature has pointed out, self-beliefs can both directly and indirectly affect different outcomes (Burnette et al., 2013). In the present research, the IT of emotional intelligence affected students' EI self-efficacy (trait EI model). The IT of emotional intelligence predicted positively the trait EI, thus, students with a more dynamic perspective of emotional intelligence had also better perceptions about their emotional competence. Students who perceive EI as a personal life domain that can be fostered through investment and time are more prone to engage in emotionalrelated experiences, adopt more functional emotional strategies and overcome challenging situations (Cabello \& Fernández-Berrocal, 2015). Thus, these students will more likely have better EI self-efficacy and consider themselves as more competent in emotional-related domains.

Although implicit theories of emotional intelligence evidenced a positive effect on students' trait EI, the same effect could not be generalized to the ability EI. On one hand, as implicit theories are individuals' personal beliefs about their capacity to develop their level of emotional intelligence and the trait EI corresponds to individuals' emotional self-efficacy, it can be argued that both are influenced by personality or trait features and therefore more likely to be significantly correlated and/or affect one another. On the other hand, the individual's subjective assessment of their capacity to change their level of emotional intelligence, might not be related to their actual capacity to perform on an emotional task, as the case in this study with the understanding emotion task. In fact, the discrepancy in the implicit theories and the actual performance might be related to students' lack of opportunities to receive constructive and accurate feedback about their emotional-related performance or even to the individuals' lower capacity of assessment and insight on those domains.

The literature in the field underlies that IT can affect achievement directly, although at lower magnitude (Burnette et al., 2013; Costa \& Faria, 2018). Nonetheless, in this study, IT of emotional intelligence failed to predict directly students' GPA. These findings might be related to diverse aspects. First-of-all, IT tends to predict performance in different contexts, although it also been documented a higher predictive power in specific-domain outcomes (Romero et al., 2014). In this case, the freshman students' perspective of emotional intelligence development or fixedness did not affect their academic realization. Perhaps this result can be due to the domain-specificity of the ITEI construct, which could more clearly be manifested 
in the prediction of emotional-related outcomes than the academic ones, such as the GPA indicator.

Moreover, the adaptive effect of IT of emotional intelligence on students' academic achievement could stand out in specific or challenging academic contents such as, for instances, mathematics, which has been associated in the literature with more negative emotions (Sutter-Brandenberger, Hagenauer, \& Hascher, 2018), while a global indicator of achievement might mask a specific effect.

Although the implicit theories of emotional intelligence were not a significant predictor of students' GPA, they affected positively all the emotional variables in the trait EI model which in turn predicted academic outcomes. These findings may indicate that IT of emotional intelligence can indirectly contribute to students' achievement, by reinforcing students' self-perceptions of emotional intelligence. Students with better self-perceptions of emotional intelligence perhaps will more likely use adaptive emotional strategies which in turn can affect their academic endeavours.

The literature has shown that implicit theories tend to influence and harmonize the self-regulatory processes which lead to achievement (Burnette et al., 2013). Particularly in this case, students' implicit theories might also affect the emotional components of the self-regulatory processes, specifically those underlying higher levels of emotional expression, understanding and management, and contribute to more easily overcoming academically challenging situations. Students' beliefs of emotional intelligence can, therefore, affect how they perceive themselves in emotional situations in the academic context, which will affect their academic experience and effectively on their achievement.

As expected according to the literature, the ability and trait EI positively predicted students' final grades (Costa \& Faria, 2015; Perera \& DiGiacomo, 2013; Song et al., 2010). A moderate significant prediction of the performance-based measure of EI, VET, was found for students' achievement $(\beta=.44, p<.001)$, confirming previous results demonstrating that the higher the students' understanding of the emotional level, the more likely they will obtain better grades. The moderate predictive power of the ability-based EI measure can be explained by the type of cognitive task proposed to the student, which is close to the learning schools' activities and therefore more strongly related to academic achievement (Costa \& Faria, 2015; O’Connor \& Little, 2003).

Though trait EI is a relevant aspect in students' success, the literature confirmed the more limited predicting power of the self-report measures of EI (Costa \& Faria, 2015; Petrides et al., 2004). In this study, only students' perceptions of their competence to express emotion and to manage and regulate emotion significantly predicted their achievement, though at a lower level than ability EI. Students' selfefficacy regarding their ability to manage their and others' emotions can be particularly determinant to effectively cope with negative emotions than can emerge in the academic context and impair achievement. Bearing in mind that the secondary 
school cycle is academically and personally demanding, students who believe they can master the more complex emotional abilities, and regulate possible negative emotions to more positive states, are more likely to succeed academically.

Another interesting result of this study was that students' emotional expression predicted negatively their achievement at the end of the year. Although the literature evidenced that better levels of emotional expression, as any other EI skills, would have a positive effect on performance, in this study considering the transition to more complex and demanding academic cycle, the externalized emotional response might not be valued in this academic context, and perhaps seen as not adjusted or misfit. In a school cycle with a particularly demanding curriculum, as is the secondary school, the academic context might tend to overlook students' emotional competencies in regard of the traditional academic contents and undervalue the process of emotional development.

To address the last objective, the moderating effect of students' gender and socio-professional status were explored. In general, there were no substantial differences in the explored model concerning gender and socio-professional status, reflecting the interrelationship similarity of the effects of implicit theories and EI on students' achievement.

The present study had limitations that further research should continue to address. In particular, although this study aimed to explore a specific, important and complex transitional academic year, the first year of the secondary cycle, the crosssectional nature of the study limited further analysis, namely, the exploration of possible differential paths of IT and EI and its effects on GPA across different secondary academic grades. Moreover, the inclusion of subject-specific academic grades (e.g., mathematics, linguistics or science), different academic indicators such as students' attendance rate, participation in class, behavioural patterns, and students' qualitative perceptions of satisfaction and adaptation to school, could deepen the potential predictive power of IT and EI on academic outcomes. Also, the use of other performance EI indicator (e.g., based on more complex dimensions such as managing and regulating emotion) might have provided a different standpoint on the effects of ITEI and EI on students' academic achievement model. For these reasons, future research should extend work in this field, particularly by investigating the prediction of IT and EI regarding students' academic outcomes in earlier scholastic phases, where the greater diversity of students' cognitive and behavioural types could extend the prediction of the variables under analysis. To corroborate these findings, further studies should continue to analyse the possible differential effect of gender and socioeconomic factors on students' achievement and analyse whether the inclusion of other sociodemographic and academic features might have reflex on the proposed model. 


\section{Conclusion}

The present study extends previous work by deepening the effects of IT and EI in the secondary academic context, which are significant predictors of students' adaptation, well-being and achievement. In particular, this research contributed to extant knowledge by confirming the direct effect of EI (ability and trait EI) on students' achievement and by exploring the effect of implicit theories of EI on students' emotional ability and self-efficacy, which in turn predicted their achievement. Furthermore, differences between students' gender and socioprofessional status were not found for the IT and EI prediction of students' GPA. These findings suggest essential implications for educational settings. Following recent research and illustrated here, students' motivational and emotional functioning should be addressed and prioritized to improve scholastic attainment. The development of socioemotional learning and the exploration of students' motivational self-beliefs about school-related outcomes should be considered either in everyday classroom, through curricula or non-formal education, and in specific target-interventions or programs, since it is acknowledged that they have an impact on learning and achievement.

The present study represented a preliminary effort at exploring whether and how implicit theories of emotional intelligence and emotional intelligence are related and affect student achievement, thus contributing to enhancing our knowledge of students' motivational and emotional functioning in the academic context.

\section{References}

Argyle, M., \& Lu, L. (1990). Happiness and social skills. Personality and Individual Differences, 11, 1255-1261. doi:10.1016/0191-8869(90)90152-H

Brackett, M. A., Mayer, J. D., \& Warner, R. M. (2004). Emotional intelligence and its relation to everyday behavior. Personality and Individual Differences, 36, 1387-1402. doi:10.1016/S0191-8869(03)00236-8

Burnette, J. L., O’Boyle, E. H., VanEpps, E. M., Pollack, J. M., \& Finkel, E. J. (2013). Mindsets matter: A meta-analytic review of implicit theories and self-regulation. Psychological Bulletin, 139, 655-701. doi:10.1037/a0029531

Cabello, R., \& Fernández-Berrocal, P. (2015). Implicit theories and ability emotional intelligence. Frontiers in Psychology, 6, 700. doi:10.3389/fpsyg.2015.00700

Claro, S., Paunesku, D., \& Dweck, C. S. (2016). Growth mindset tempers the effects of poverty on academic achievement. Proceedings of the National Academy of Sciences of the United States of America, 113, 8664-8668. doi:10.1073/pnas.1608207113 
Costa, A., \& Faria, L. (2015). The impact of emotional intelligence on academic achievement: A longitudinal study in Portuguese secondary school. Learning and Individual Differences, 37, 38-47.

Costa, A., \& Faria, L. (2018). Implicit theories of intelligence and academic achievement: A meta-analytic review. Frontiers in Psychology, 9, 829. doi:10.3389/fpsyg.2018.00829

Costa, A., \& Faria, L. (2020). Construção e validação da Escala de Teorias Implícitas de Inteligência Emocional (TIIE) no contexto escolar [Construction and validation of the Implicit Theories of Emotional Intelligence Scale (TIIE) in the school context]. Revista Iberoamericana de Diagnóstico y Evaluación - e Avaliação Psicológica, 54, 57-68. doi:10.21865/ridep54.1.05

Costa, A., Faria, L., \& Takšic, V. (2011). Vocabulary of Emotions Test (VET): A crosscultural validation in Portuguese and Croatian contexts. Psychological Topics, 21(3), 413-424.

Côté, S., Gyurak, A., \& Levenson, R. W. (2010). The ability to regulate emotion is associated with greater well-being, income, and socioeconomic status. Emotion, 10, 923-933. doi:10.1037/a0021156

Crum, A. J., Salovey, P., \& Achor, S. (2013). Rethinking stress: The role of mindsets in determining the stress response. Journal of Personality and Social Psychology, 104(4), 716-733. doi:10.1037/a0031201

De Castella, K., Goldin, P., Jazaieri, H., Ziv, M., Dweck, C. S., \& Gross, J. J. (2013). Beliefs about emotion: Links to emotion regulation, well-being, and psychological distress. Basic and Applied Social Psychology, 35, 497-505. doi:10.1080/01973533. 2013.840632

Díaz-Herrero, Á., Gonzálvez, C., Sanmartín, R., Vicent, M., Lagos-San Martín, N., Inglés, C. J., \& García-Fernández, J. M. (2018). Profiles of emotional intelligence and demotivation to attend school in Chilean adolescents. Motivation and Emotion, 42(6), 947-959. doi:10.1007/s11031-018-9712-4

Duckworth, A. L., \& Seligman, M. E. P. (2005). Self-discipline outdoes IQ in predicting academic performance of adolescents. Psychological Science, 16(12), 939-944. doi:10.1111/j.1467-9280.2005.01641.x

Dweck, C. S. (1999). Self-theories: Their role in motivation, personality, and development. Philadelphia, PA: Psychology Press.

Dweck, C. S. (2012). Implicit theories. In P. Van Lange, A. Kruglanski, \& T. Higgins (Eds.), The handbook of theories of social psychology (pp. 43-62). London: Sage Publications Ltd.

Dweck, C. S., \& Leggett, E. L. (1988). A social-cognitive approach to motivation and personality. Psychological Review, 95, 256-273. doi:10.1037/0033-295X.95.2.256 
Elliot, A. J., \& Dweck, C. S. (2005). Competence and motivation: Competence as the core of achievement motivation. In A. J. Elliot \& C. S. Dweck (Eds.), Handbook of competence and motivation (pp. 3-12). New York: The Guilford Press.

Faria, L., Lima Santos, N., Takšić, V., Raty, H., Molander, B., Holmström, S., ... Toyota, H. (2006). Cross-cultural validation of the Emotional Skills and Competence Questionnaire (ESCQ). Psicologia, 2, 95-127.

Fernández-Berrocal, P., Cabello, R., Castillo, R., \& Extremera, N. (2012). Gender differences in emotional intelligence: The mediating effect of age. Behavioral Psychology/ Psicologia Conductual, 20, 77-89.

Gil-Olarte, M. P. G., Martin, R. P., \& Brackett, M. A. (2006). Relating emotional intelligence to social competence and academic achievement in high school students. Psicothema, $18,118-123$.

Greenberg, M. T., Weissberg, R. P., O’Brien, M. U., Zins, J. E., Fredericks, L., Resnik, H., \& Elias, M. J. (2003). Enhancing school-based prevention and youth development through coordinated social and emotional learning. American Psychologist, 58, 466-474. doi:10.1037/0003-066X.58.6-7.466

Henderson, V., \& Dweck, C. (1990). Adolescence and achievement. In S. Feldman \& G. Elliott (Eds.), At the threshold: Adolescent development (pp. 308-329). Cambridge, MA: Harvard University Press.

Hong, Y., Chiu, C., Dweck, C. S., Lin, D. M. S., \& Wan, W. (1999). Implicit theories, attributions and coping: A meaning system approach. Journal of Personality and Social Psychology, 77, 588-599. doi:10.1037/0022-3514.77.3.588

Hu, L., \& Bentler, P. M. (1999). Cutoff criteria for fit indexes in covariance structure analysis: Conventional criteria versus new alternatives. Structure Equation Modeling, 6, 1-55. doi:10.1080/10705519909540118

Joseph, D. L., \& Newman, D. A. (2010). Emotional intelligence: An integrative meta-analysis and cascading model. Journal of Applied Psychology, 95(1), 54-78. http://dx.doi.org/ $10.1037 / \mathrm{a} 0017286$

Kappes, A., \& Schikowski, A. (2013). Implicit theories of emotion shape regulation of negative affect. Cognition and Emotion, 27(3), 1-9. doi:10.1080/02699931.2012. 753415

Lau, S., \& Roeser, R. W. (2002). Cognitive abilities and motivational processes in high school students' situational engagement and achievement in science. Educational Assessment, 8(2), 139-162. doi:10.1207/S15326977EA0802_04

Mavroveli, S., Petrides, K., Shove, C., \& Whitehead, A. (2008). Investigation of the construct of trait emotional intelligence in children. European Child \& Adolescent Psychiatry, 17, 516-526. https://doi.org/10.1007/s00787-008-0696-6 
Mavroveli, S., \& Sánchez-Ruiz, M. J. (2011). Trait emotional intelligence influences on academic achievement and school behaviour. British Journal of Educational Psychology, 81(1), 112-134. doi:10.1348/2044-8279.002009

Mayer, J. D., \& Salovey, P. (1997). What is emotional intelligence? In P. Salovey \& D. Sluyter (Eds.), Emotional development and emotional intelligence: Educational applications (pp. 3-31). New York: Basic Books.

Mayer, J. D., Caruso, D., \& Salovey, P. (1999). Emotional intelligence meets traditional standards for an intelligence. Intelligence, 27, 267-298. doi:10.1016/S0160-2896(99) 00016-1

Mestre, J., Guil, R., Lopes, P., Salovey, P., \& Gil-Olarte, P. (2006). Emotional intelligence and social and academic adaptation to school. Psicothema, 18(1), 112-117.

Morris, A. S., Silk, J. S., Steinberg, L., Myers, S. S., \& Robinson, L. R. (2007). The role of the family context in the development of emotion regulation. Social Development, 16, 361-388. doi:10.1111/j.1467-9507.2007.00389.x

Nussbaum, A. D., \& Dweck, C. S. (2008). Defensiveness versus remediation: Self-theories and modes of self-esteem maintenance. Personality and Social Psychology Bulletin, 34, 500-612. doi:10.1177/ 0146167207312960

O’Connor, R. M. Jr., \& Little, I. S. (2003). Revisiting the predictive validity of emotional intelligence: Self-report versus ability-based measures. Personality and Individual Differences, 35, 1893-1902. doi:10.1016/S0191-8869(03)00038-2

Pepi, A., Faria, L., \& Alesi, M. (2006). Personal conceptions of intelligence, self-esteem, and school achievement in Italian and Portuguese students. Adolescence, 41, 615-631.

Perera, H. N., \& DiGiacomo, M. (2013). The relationship of trait emotional intelligence with academic performance: A meta-analytic review. Learning and Individual Differences, 28, 20-33. doi:10.1016/j.lindif.2013.08.002

Petrides, K. V., Frederickson, N., \& Furnham, A. (2004). The role of trait emotional intelligence in academic performance and deviant behavior at school. Personality and Individual Differences, 36, 277-293. http://dx.doi.org/10.1016/S0191-8869(03)00084-9

Petrides, K. V., Pita, R., \& Kokkinaki, F. (2007). The location of trait emotional intelligence in personality factor space. British Journal of Psychology, 98, 273-289. doi:10.1348/ 000712606X120618

Petrides, K. V., Sanchez-Ruiz, M. J., Siegling, A. B., Saklofske, D. H., \& Mavroveli, S. (2018). Emotional intelligence as personality: Measurement and role of trait emotional intelligence in educational contexts. In K. V. Keefer, J. D. A. Parker, \& D. H. Saklofske (Eds.), Emotional intelligence in education. The Springer series on human exceptionality (pp. 49-81). Cham: Springer.

Robins, R. W., \& Pals, J. L. (2002). Implicit self-theories in the academic domain: Implications for goal orientation, attributions, affect, and self-esteem change. SelfIdentity, 1, 313-336. doi:10.1080/15298860290106805 
Rode, J. C., Mooney, C. H., Arthaud-day, M. L., Near, J. P., Rubin, R. S., Baldwin, T. T., \& Boomer, W. H. (2008). An examination of the structural, discriminant, nomological, and incremental predictive validity of the MSCEIT V2.0. Intelligence, 36, 350-366. doi:10.1016/j.intell.2007.07.002

Romero, C., Master, A., Paunesku, D., Dweck, C. S., \& Gross, J. (2014). Academic and emotional functioning in middle school: The role of implicit theories. Emotion, 14, $227-$ 234. doi:10.1037/a0035490

Sevincer, A. T., Kluge, L., \& Oettingen, G. (2014). Implicit theories and motivational focus: Desired future versus present reality. Motivation and Emotion, 38, 36-46. doi:10.1007/ s11031-013-9359-0

Sisk, V. F., Burgoyne, A. P., Sun, J., Butler, J. L., \& Macnamara, B. N. (2018). To what extent and under which circumstances are growth mind-sets important to academic achievement? Two meta-analyses. Psychological Science, 29(4), 549-571. doi:10.1177/ 0956797617739704

Song, L. J., Huang, G., Peng, K. Z., Law, K. S., Wong, C., \& Chen, Z. (2010). The differential effect of general mental ability and emotional intelligence on academic performance and social interactions. Intelligence, 38, 137-143. doi:10.1016/j.intell.2009.09.003

Stocker, J., \& Faria, L. (2012). Competência percebida no Ensino Secundário: Do conceito à avaliação através de um questionário compósito. [Competence in secondary school: From conceptualization to assessment through a composite questionnaire]. Psicologia, 21(2), 113-140.

Sutter-Brandenberger, C. C., Hagenauer, G., \& Hascher, T. (2018). Students's self-determined motivation and negative emotions in mathematics in lower secondary education Investigating reciprocal relations. Contemporary Educational Psychology, 55, 166-175. doi:10.1016/j.cedpsych.2018.10.002

Takšić, V., \& Mohorić, T. (2008, July). Vocabulary of Emotion Test (VET): Ability measure of emotional intelligence. Paper presented at the XXIX International Congress of Psychology, Berlin, Germany.

Takšić, V., Harambašić, D., \& Velemir, B. (2003). Vocabulary of Emotion Test (VET 35). Rijeka: Authors' edition.

Takšić, V., Mohorić, T., \& Duran, M. (2009a). Emotional Skills and Competence Questionnaire (ESCQ) as a self-report measure of emotional intelligence. Horizons of Psychology, 18, 7-21.

Takšić, V., Mohorić, T., Bradić, S., Faria, L., Santos, N. L., Pessoa, F., ... Jiang, Q. (2009b, September). Cross-cultural comparison of emotional skills and competencies questionnaire (ESCQ). Paper presented at the II. International Emotional Intelligence Congress, Santander, Spain. 
Tamir, M., John, O. P., Srivastava, S., \& Gross, J. J. (2007). Implicit theories of emotion: Affective and social outcomes across a major life transition. Journal of Personality and Social Psychology, 92, 731-744. doi:10.1037/0022-3514.92.4.731

Thompson, T., \& Musket, S. (2005). Does priming for mastery goals improve the performance of students with an entity view of ability? British Journal of Educational Psychology, 75, 391-409. doi:10.1348/ 000709904X22700

Van Rooy, D. L., \& Viswesvaran, C. (2004). Emotional intelligence: A meta-analytic investigation of predictive validity and nomological net. Journal of Vocational Behavior, 65, 71-95. doi:10.1016/S0001-8791(03)00076-9

Received: October 21, 2019 